\title{
Influence of the Local Food Environment on Hispanics' Perceptions of Healthy Food Access in New York City
}

Hispanic Health Care International 1-9

(C) The Author(s) 2018

Article reuse guidelines:

sagepub.com/journals-permissions DOI: 10.1 |77/I5404|53/8788068 journals.sagepub.com/home/hci (S)AGE

\author{
Manuel C. Co Jr., PhD, MS, RN, CPHIMS' ${ }^{\oplus}$ \\ and Suzanne Bakken, PhD, RN, FAAN, FACMI, FIAHSI ${ }^{2}$
}

\begin{abstract}
Introduction: Studies have characterized food environments and documented its impact on access and consumption of healthy foods as well as diet-related health conditions. This study aims to characterize the local food environment in New York City's Washington Heights and Inwood community and to examine its influence on Hispanics' perceptions of healthy food access. Methods: Person-level local food environments were created by spatially modeling food retailers selling fresh fruits and vegetables or low-fat products within a participant's 400- and 800-m residential radius buffers. Data were analyzed using multivariate binary logistic regression. Results: Fruit/vegetable markets significantly increased participants' odds of perceiving the availability of a large selection as well as the high quality of fresh fruits and vegetables in their neighborhood. Medium-/large-size supermarkets/groceries within 400-m radius significantly increased participants' odds of perceiving the high quality of fresh fruits and vegetables in their neighborhood, whereas meat markets significantly lowered the odds. Fruit/vegetable markets and medium-/ large-size supermarkets/groceries significantly increased participants' odds of perceiving the availability of a large selection of lowfat products in their neighborhood. Conclusion: Study findings advance our understanding of the relationships between local food environment and perceived healthy food access among urban Hispanics.
\end{abstract}

\section{Keywords}

food environment, food outlets, GIS, healthy food access, Hispanic, Latino, perceptions

Where one lives and works can influence health. Studies have examined the food environment's influence on one's dietary choices. Easy access to inexpensive, energy-dense foods from bodegas or small convenience stores near schools and a high density of fast food outlets in low-income neighborhoods can influence school-age children and adolescents' food choices over the years (Bauer, Larson, Nelson, Story, \& NeumarkSztainer, 2009; Casey et al., 2014; Fox, Dodd, Wilson, \& Gleason, 2009; Neckerman et al., 2010; Thornton et al., 2016). Studies have also examined the influence of food environment on body mass index (BMI), diabetes, and other diet-related health conditions such as cardiovascular disease and hypertension.

A secondary data analyses of the New York City Community Healthy Survey showed positive association between the proportion of unhealthy food outlets and BMI as well as its strong association with lower poverty ZIP codes (Stark et al., 2013). Higher rates of obesity, diabetes, and other diet-related health conditions have been reported in lower-income minority communities that have higher-than-average access to convenience stores and fast food restaurants and limited access to healthy foods at reasonable cost (Auchincloss et al., 2009; Black, Macinko, Dixon, \& Fryer, 2010; Bodor, Rice, Farley, Swalm, \& Rose, 2010b; Morland \& Evenson, 2009; Mujahid et al., 2008; Zenk et al., 2005; Zenk, Thatcher, Reina, \& Odoms-Young, 2015). Conversely, greater availability of grocery stores and supermarkets within a short distance from home was associated with lower rates of obesity, lower BMI, and lower diastolic blood pressure (Dubowitz et al., 2012).

The local food environment varies by race and ethnic composition of the neighborhood, with more supermarkets and chain grocery stores, and fewer food outlets with highdensity foods (e.g., bodegas, convenience stores, fast food restaurants) in predominantly White as compared with Hispanic or African American neighborhoods (Ball, Timperio, \& Crawford, 2009; Bodor, Rice, Farley, Swalm, \& Rose, 2010a; Dubowitz et al., 2015; Odoms-Young, Zenk, \& Mason, 2009; Schulz et al., 2013; Smoyer-Tomic et al., 2008). Variation in food retailer type is associated with differences in the availability of fresh and organic produce and clinician-recommended foods for those

\footnotetext{
' Hunter College of the City University of New York, New York, NY, USA

${ }^{2}$ Columbia University, New York, NY, USA

Corresponding Author:

Suzanne Bakken, Columbia University School of Nursing and Department of Biomedical Informatics, 560 West I68th Street, New York, NY 10032, USA. Email: sbh22@columbia.edu
} 
with diabetes (Horowitz, Colson, Hebert, \& Lancaster, 2004; Morland \& Filomena, 2007; Powell, Slater, Mirtcheva, Bao, \& Chaloupka, 2007). This variation also influence food prices with foods costing more in convenience stores compared with grocery stores and supermarkets (Liese, Weis, Pluto, Smith, \& Lawson, 2007). Consequently, chain supermarkets' minimal presence in Hispanic and African American neighborhoods may limit not only the variety of higher quality food products available to residents but also the availability at affordable prices for such products (Horowitz et al., 2004; Laraia, Hendrickson, \& Zhang, 2015).

The local food environment influences fruit and vegetable consumption. A study conducted in Maryland, Minnesota, Mississippi, and North Carolina found that the presence of at least one supermarket, as compared with no supermarket, in census tract was positively associated with higher proportion of African Americans meeting the fruit and vegetable dietary guidelines (Morland, Wing, \& Diez Roux, 2002). Similarly, studies have reported greater availability of fresh fruits and vegetables in the neighborhood, regardless of the type of food store, and the presence of large grocery store in the neighborhood being associated with higher daily average consumption of fruits and vegetables among Latinos compared with African Americans (Bodor, Rose, Farley, Swalm, \& Scott, 2007; Laraia et al., 2015; Zenk et al., 2009).

Studies that examined both the objective and perceived food environment measures have reported mixed findings. Store density showed direct association with perceived healthy foods availability (Moore, Diez Roux, \& Brines, 2008). Conversely, other studies found poor correlation between objective and perceived food environment measures (Barnes, Bell, Freedman, Colabianchi, \& Liese, 2015; Caspi, Kawachi, Subramanian, Adamkiewicz, \& Sorensen, 2012; Gustafson et al., 2011; Lucan, Hillier, Schechter, \& Glanz, 2014).

The literature suggests that local food environment influences fruit and vegetable consumption as well as health. Multiple studies have also documented variation in healthy food access and costs between neighborhoods that are predominantly White as compared with African American or Hispanic. However, little is known about the relationship between objective food environment measures and Hispanics' perceptions of healthy food access. This is particularly relevant due to the growth of Hispanic population in the United States (Passel, Cohn, \& Lopez, 2011; U.S. Census Bureau, 2015). Consequently, understanding the relationship between objective and perceived measures provides an important foundation for the development of interventions to increase Hispanics' fruit and vegetable consumption to a level consistent with dietary guidelines. The aims of this study were to characterize the local food environment in New York City's Washington Heights and Inwood community and to examine the influence of local food environment on Hispanics' perceptions of healthy food access in their neighborhood.

\section{Method}

\section{Study Design}

This cross-sectional observational study was undertaken as part of the larger Washington Heights/Inwood Informatics Infrastructure for Comparative Effectiveness Research (WICER) Project and supports WICER's overall goal of gaining a comprehensive understanding of those living in Northern Manhattan by contributing to our understanding of the influence of place on health among urban Hispanics. The Columbia University Medical Center Institutional Review Board approved all study procedures.

\section{Study Setting}

The study was conducted in Northern Manhattan's Washington Heights and Inwood neighborhoods (postal ZIP codes 10031, 10032, 10033, 10034, and 10040), a predominantly Hispanic community in New York City. Almost half of its residents (48\%) are foreign-born, about two in five residents (39\%) have limited English proficiency, about a third of its residents (30\%) have less than a high school education, about a third of its residents $(27 \%)$ live below the federal poverty level, about one in five residents (22\%) are obese, and about 1 in 10 residents (10\%) are diabetic (King et al., 2015).

\section{Participant Recruitment and Sampling Methods}

Participants who were 18 years or older and spoke either English or Spanish were recruited for the WICER study between 2010 and 2013. A random household sampling approach was initially employed for participants recruited in residential households, but sampling evolved over time to snowball sampling per study design. A convenience sample was also recruited from the Ambulatory Care Network clinics of NewYork-Presbyterian/Columbia University Medical Center and in community settings such as schools and grocery stores.

\section{Inclusion and Exclusion Criteria}

The inclusion criteria for this study were Hispanic ethnicity, speak English or Spanish, 18 years or older, have valid measures for key variables of interest, and reside in one of the five Northern Manhattan ZIP codes. The exclusion criteria were inability to provide informed consent in English or Spanish and not meeting inclusion criteria.

\section{Data Collection Procedures: WICER Survey}

After informed consent was obtained, bilingual community health workers administered the WICER survey via faceto-face interview in the participant's language of choice. Survey and other measures were documented on paper or iPad tablet computer. Each interview lasted about 45 to 60 minutes. 


\section{Data Extraction Procedures: Retail Food Outlets}

Consistent with other studies that examined the availability of healthy foods or the presence of healthy food outlets in the local community being studied (Jack et al., 2013; Larson, Story, \& Nelson, 2009; Rundle et al., 2009; Stark et al., 2013; Walker, Keane, \& Burke, 2010), relevant retail food outlets were identified using the ReferenceUSA (Infogroup, Papillion, Nebraska) 2013 business database. The information in this database is verified and updated annually by the ReferenceUSA staff. Information extracted from the database was company name, address, location type (single location or branch), franchise description, employee size, location square footage, and North American Industry Classification System (NAICS) codes and descriptions. NAICS is the standard used by federal statistical agencies to classify business establishments for the purpose of collecting, analyzing, and publishing statistical data related to the U.S. business economy (U.S. Census Bureau, 2013). To ensure data validity, the first author viewed locations on the web and visited addresses to establish "ground truth" of the retail food outlets. These procedures confirmed the store's food outlet classification and location address as well as the availability of fresh fruits and vegetables or low-fat products in the store.

\section{Measures and Variables}

Study measures and variables were sociodemographics, fruit and vegetable consumption, perceived healthy food access, and retail food outlets. The sociodemographic characteristics were age, gender, marital status (partnered, not partnered), nativity (U.S.-born, foreign-born: Dominican Republic, foreign-born: Other), survey language preference, education (less than high school, high school, and more than high school), employment status (employed, not employed), and health insurance (government or private insurance, no insurance).

Fruit and vegetable consumption was measured by three WICER survey questions: (1) During the past 30 days, not counting juice, how many times per day, week, or month did you eat fruit, include fresh, frozen, or canned fruit? (2) During the past 30 days, how many times per day, week, or month did you eat dark green vegetables? and (3) Not counting what you just told me, during the past 30 days, about how many times per day, week, or month did you eat other vegetables? Responses were standardized to the "per day" unit of reference and then dichotomized to indicate participant's not consuming or consuming the federal minimum daily recommendation of two servings of fruits and three servings of vegetables, respectively (Centers for Disease Control and Prevention, 2005; Guthrie, 2004).

The perceived healthy food access outcome variables were measured using three WICER survey items: (1) A large selection of fresh fruits and vegetables is available in my neighborhood. (2) The fresh fruits and vegetables in my neighborhood are of high quality. (3) A large selection of low-fat products is available in my neighborhood. For each item, the 4-point
Likert-type scale response (Strongly disagree, Disagree, Agree, and Strongly agree) was dichotomized into Disagree and Agree.

The predictor variables included retail food outlets in the neighborhood. The NAICS descriptions enabled us to distinguish supermarkets and grocery stores from the smaller convenience stores, which carry higher number of caloriedense convenience food items that are of lower nutritional value (Morland, Diez Roux, \& Wing, 2006; Morland \& Evenson, 2009). The relevant NAICS codes and descriptions are as follows:

- 445110-Small: Supermarkets/other groceries (excluding convenience stores) are single-location stores with up to nine employees and can have up to 2,499 square feet of store space

- 445110-Medium: Supermarkets/other groceries (excluding convenience stores) are single-location stores or a branch of another store with up to 99 employees and have between 2,500 and 9,999 square feet of store space

- 445110-Large: Supermarkets/other groceries (excluding convenience stores) are a branch of another store with up to 249 employees and have 40,000 or more square feet of store space

- 445210: Meat markets are single-location stores with up to 49 employees and have between 2,500 and 9,999 square feet of store space

- 445230: Fruit/vegetable markets are single-location stores with less than five employees and can have up to 2,499 square feet of store space

Based on frequencies and distributions, four retail food outlet variables were created: fruit/vegetable markets (categorical; $0,1,>1$ ), meat markets (categorical; 0, 1), small-size supermarkets/groceries (continuous), and medium-/large-size supermarkets/groceries (continuous).

Participant's residential addresses and food retailer location addresses were geocoded to transform postal address into their corresponding latitude and longitude geographic coordinates on a map. To model the person-level local food environment, Euclidean-based radius buffers were created by calculating the 400-m (about 0.25-mile) and 800-m (about 0.5-mile) distances from the center of the participant's geocoded residential address to the center of the food retailer's geocoded location address. All geocoding and spatial modeling were performed using ArcGIS 10.1 (ESRI, Redlands, CA).

\section{Data Management}

WICER survey data were stored and managed using REDCap (Research Electronic Data Capture) for data validation and integrity checks to ensure data quality (Harris et al., 2009). Data were also assessed for errors and/or missing values; and participants were excluded from the analysis if they had missing data on one or more key study variables. Data were analyzed using SPSS 23 (IBM SPSS Inc., Chicago, IL). 


\section{Data Analysis}

Descriptive statistics were used to report the sociodemographic characteristics of study participants and the Northern Manhattan's local food environment. Bivariate (single predictor) analyses were performed for each of the three perceived healthy food access outcome variables. All predictor variables having an alpha level of significance at the $p<.20$ in the bivariate analyses were then entered into the multivariate binary logistic regression analyses using the backward elimination method (Hosmer \& Lemeshow, 2000; Mickey \& Greenland, 1989). Two regression models (400-m and 800-m radius buffers) were run for each of the three outcome variables. Statistical significance was set at the $p<.05$ level for the multivariate analyses. Model fit was measured using Hosmer-Lemeshow test.

Table I. Sample Characteristics, Fruit and Vegetable Consumption, and Perceived Healthy Food Access.

\begin{tabular}{|c|c|}
\hline Sample characteristics $(N=4,019)$ & $\begin{array}{l}n(\%) \text { or } \\
M \pm S D\end{array}$ \\
\hline \multicolumn{2}{|l|}{ Age } \\
\hline Female & $50 \pm 16.4$ \\
\hline Male & $49.2 \pm 17.7$ \\
\hline \multicolumn{2}{|l|}{ Gender } \\
\hline Female & $2,950(73.4 \%)$ \\
\hline Male & $1,049(26.1 \%)$ \\
\hline Not answered & $20(0.5 \%)$ \\
\hline Marital status: Partnered & $1,443(36 \%)$ \\
\hline \multicolumn{2}{|l|}{ Nativity } \\
\hline U.S.-born & $514(12.8 \%)$ \\
\hline Foreign-born: Dominican Republic & $3,130(77.9 \%)$ \\
\hline Foreign-born: Other & $368(9.2 \%)$ \\
\hline Not answered & $7(0.2 \%)$ \\
\hline \multicolumn{2}{|l|}{ Survey language preference } \\
\hline English & $953(23.7 \%)$ \\
\hline Spanish & $3,066(76.3 \%)$ \\
\hline \multicolumn{2}{|l|}{ Education } \\
\hline Less than high school & $2,078(5 \mathrm{I} .7 \%)$ \\
\hline High school graduate & $860(21.4 \%)$ \\
\hline More than high school & I,08I (26.9\%) \\
\hline Employed & $2,3 \mid 4(57.6 \%)$ \\
\hline Health insurance: Insured & $3,916(97.4 \%)$ \\
\hline Insurance type: Medicare/Medicaid & $3,095(77 \%)$ \\
\hline Fruit consumption: $\geq 2$ servings/day & $376(9.4 \%)$ \\
\hline Vegetable consumption: $\geq 3$ servings/day & $239(5.9 \%)$ \\
\hline \multicolumn{2}{|l|}{ Perceived healthy food access in the neighborhood } \\
\hline $\begin{array}{l}\text { Availability and selection of fresh fruits and } \\
\text { vegetables: Agree }\end{array}$ & $3,429(86 \%)$ \\
\hline High quality of fresh fruits and vegetables: Agree & $3,297(82.7 \%)$ \\
\hline Availability and selection of low-fat products: Agree & $3,274(82 \%)$ \\
\hline
\end{tabular}

\section{Results}

Demographic characteristics of the 4,019 Hispanic participants are summarized in Table 1. Participants' mean ages were $49 \pm$ 17.7 for males and $50 \pm 16.4$ years for females. The majority of participants were females (73.4\%), foreign-born Dominicans (77.9\%), interviewed in Spanish (76.3\%), employed (57.6\%), and had Medicare and/or Medicaid (77\%) as health insurance. About half had a high school or higher education, and 36\% were partnered. About 1 in 10 participants $(9.4 \%)$ consumed the recommended two or more daily servings of fruits, and about 1 in 20 participants (5.9\%) consumed the recommended three or more daily servings of vegetables. More than $80 \%$ agreed that a large selection of fresh fruits and vegetables was available and of high quality, and that a large selection of lowfat products was available.

A total of 165 retail food outlets that carry fresh fruits and vegetables or low-fat products were included in this study. The food environment landscape in Northern Manhattan (Figure 1) includes fruit/vegetable markets, meat markets, and supermarkets/groceries (Table 2). The majority of the food retailers $(91.5 \%)$ were single-location stores and most were small or medium in size. Food retailers that are a branch of another store were medium or large in size and accounted for $8.5 \%$ of the total food outlets.

Participants' access to food retailers in their respective $400-\mathrm{m}$ and $800-\mathrm{m}$ residential radii is presented in Table 2 . About three in four of the participants (76.5\%) have access to fruit/vegetable markets in their $400-\mathrm{m}$ radius and that number increased to $98.2 \%$ in their $800-\mathrm{m}$ radius. About a third of the participants $(34.2 \%)$ have access to a meat market in their 400$\mathrm{m}$ radius and that number almost doubled in their $800-\mathrm{m}$ radius. Almost everyone has access to small-size (99.7\%) and medium-/large-size (96.7\%) supermarkets/groceries in their $400-\mathrm{m}$ radius, and those numbers increased to $100 \%$ in their $800-\mathrm{m}$ radius.

For perceived availability and selection of fresh fruit and vegetables in the neighborhood, fruit/vegetable markets and meat markets met the $p<.20$ criterion for entry into the multivariate analysis for the 400-m radius model, and these variables along with small-size supermarkets/groceries met the entry criterion for the $800-\mathrm{m}$ radius model. The presence of more than one fruit/vegetable market within 400-m radius and the presence of one or more fruit/vegetable markets within 800-m radius significantly increased the participant's odds of perceiving that a large selection of fresh fruits and vegetables is available in their neighborhood (Table 3). The Hosmer-Lemeshow tests demonstrated good fit for the 400-m model $\left(\chi^{2}=2.52, p=.641\right)$ and poor fit for the $800-\mathrm{m}$ model $\left(\chi^{2}=18.798, p=.016\right)$.

For perceived quality of fruits and vegetables in the neighborhood, three food outlet types (fruit/vegetable markets, meat markets, and medium-/large-size supermarkets/groceries) met the criterion for entry into the multivariate analysis for the 400$\mathrm{m}$ radius model, and the first two food outlet types also met the criterion for the $800-\mathrm{m}$ radius model. The presence of more than one fruit/vegetable markets and medium-/large-size supermarkets/groceries within 400-m radius, and one or more fruit/ vegetable markets within $800-\mathrm{m}$ radius significantly increased the odds of participants perceiving that the fresh fruits and vegetables in their neighborhood are of high quality (Table 4). The presence of meat markets in both $400-\mathrm{m}$ and $800-\mathrm{m}$ radii significantly lowered the odds. The 


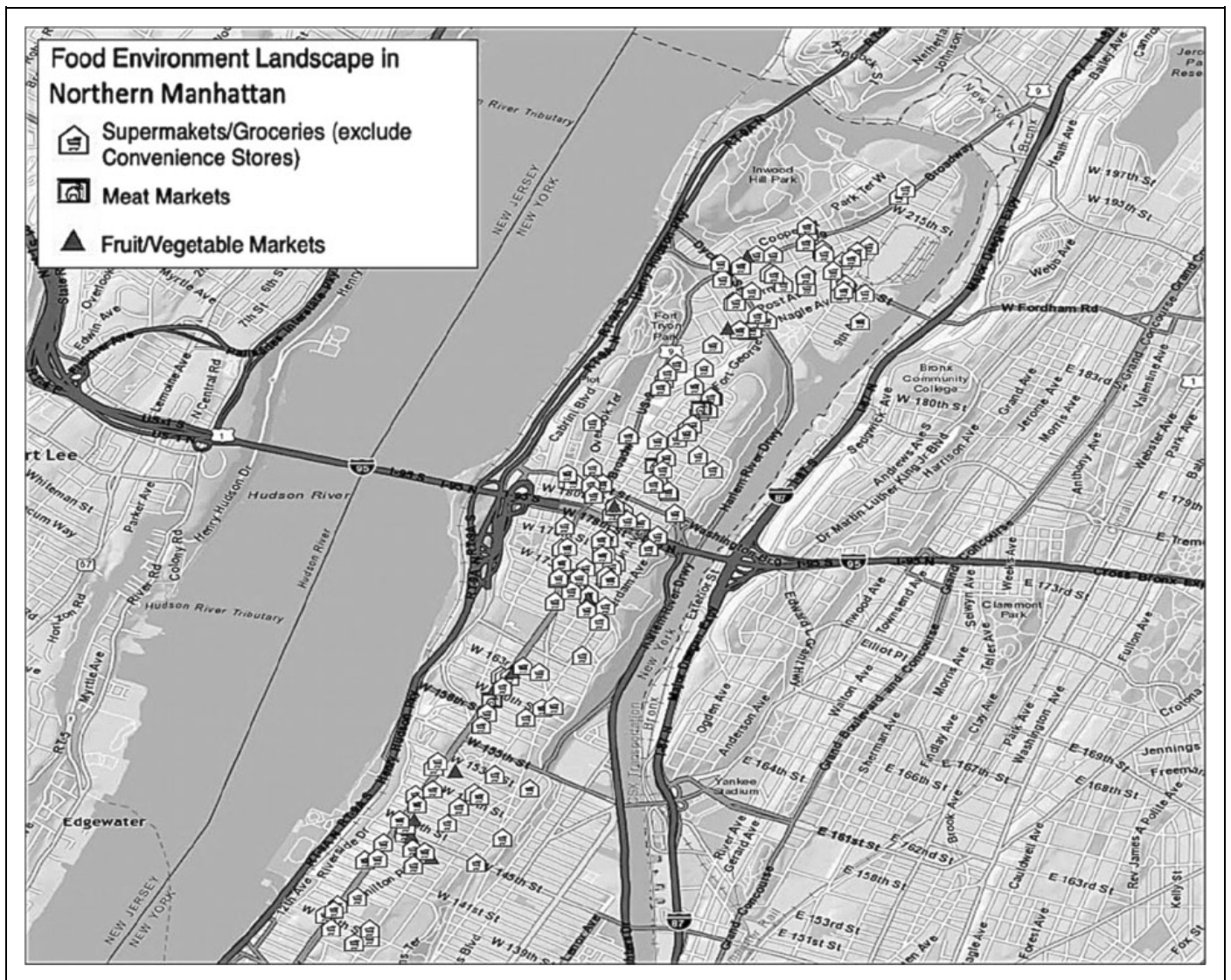

Figure I. Food environment landscape in Northern Manhattan.

Table 2. Descriptive Statistics of the Local Food Environment.

\begin{tabular}{|c|c|c|c|c|c|c|c|c|}
\hline \multirow[b]{2}{*}{ Food retailers } & \multicolumn{5}{|c|}{ Study setting ZIP codes } & \multirow[b]{2}{*}{ Store, $n(\%)$} & \multicolumn{2}{|c|}{ Participant access, $n(\%)$} \\
\hline & 10031 & 10032 & 10033 & 10034 & 10040 & & $400 \mathrm{~m}$ & $800 \mathrm{~m}$ \\
\hline Meat market & & I & I & & i & $3(1.8 \%)$ & $\mathrm{I}, 374(34.2 \%)$ & $2,602(64.7 \%)$ \\
\hline Supermarket/grocery (medium/large size) ${ }^{\mathrm{a}}$ & 6 & 8 & 9 & 5 & 6 & $34(20.6 \%)$ & $3,886(96.7 \%)$ & $4,019(100 \%)$ \\
\hline Supermarket/grocery (small size) ${ }^{\mathrm{a}}$ & 23 & 16 & 34 & 23 & 21 & $117(70.9 \%)$ & $4,006(99.7 \%)$ & $4,019(100 \%)$ \\
\hline
\end{tabular}

${ }^{a}$ Excludes convenience store.

Hosmer-Lemeshow tests indicated that the overall model fit was good (400-m model: $\chi^{2}=9.859, p=.275 ; 800-\mathrm{m}$ model: $\left.\chi^{2}=7.25, p=.51\right)$.

For perceived availability and selection of low-fat products in the neighborhood, fruit/vegetable markets, meat markets, and medium-/large-size supermarkets/groceries met the criterion for entry into the multivariate analysis for the $400-\mathrm{m}$ radius. These variables plus small-size supermarkets/groceries met the criterion for entry in the $800-\mathrm{m}$ radius analysis. The presence of more than one fruit/vegetable markets and medium-/large-size supermarkets/groceries in both $400-\mathrm{m}$ and $800-\mathrm{m}$ radii significantly increased participant's odds of perceiving that a large selection of low-fat products is available in their neighborhood, whereas the presence of meat markets within the 400-m radius significantly lowered the odds (Table 5 ). The presence of small-size supermarkets/groceries within the 800 -m radius did not have much influence on their perceived availability and selection of low-fat products in the neighborhood. The Hosmer-Lemeshow tests indicated that the overall model fit is good (400-m model: $\chi^{2}=11.548, p=.173 ; 800-\mathrm{m}$ model: $\left.\chi^{2}=6.308, p=.613\right)$.

\section{Discussion}

In characterizing the objective measures of the local food environment, we found that the majority of our urban Hispanic participants have access to fruit/vegetable markets and smallsize and medium-/large-size supermarkets/groceries in their respective $400-\mathrm{m}$ and $800-\mathrm{m}$ residential radii. Our findings that the majority of retail food outlets $(91.5 \%)$ are single-location 
Table 3. Multivariate Binary Logistic Regressions for Predicting Perceived Availability and Selection of Fresh Fruits and Vegetables in the Neighborhood.

\begin{tabular}{|c|c|c|}
\hline Objective local food environment measures & OR $[95 \% \mathrm{Cl}]$ & $p$ \\
\hline \multicolumn{3}{|l|}{ Fruit/vegetable markets in $400 \mathrm{~m}$} \\
\hline None & 1.00 & \\
\hline I store & $1.19[0.96,1.49)$ & .119 \\
\hline$>$ I stores & $1.67[1.22,2.29]$ & .001 \\
\hline \multicolumn{3}{|l|}{ Meat markets in $400 \mathrm{~m}$} \\
\hline No & 1.00 & \\
\hline Yes & $0.82[0.66,1.00]$ & .052 \\
\hline \multicolumn{3}{|l|}{ Fruit/vegetable markets in $800 \mathrm{~m}$} \\
\hline None & 1.00 & \\
\hline I store & $2.21[1.20,4.06]$ & $.01 \mathrm{I}$ \\
\hline$>$ I stores & $3.01[1.69,5.36]$ & .000 \\
\hline Supermarkets/groceries (small size) in $800 \mathrm{~m}$ & $0.99[0.98,1.00]$ & .050 \\
\hline
\end{tabular}

Note. $\mathrm{OR}=$ odds ratio; $\mathrm{Cl}=$ confidence interval. Boldfaced $p$ values indicate statistical significance $(p<.05)$.

Table 4. Multivariate Binary Logistic Regressions for Predicting Perceived High Quality of Fresh Fruits and Vegetables in the Neighborhood.

\begin{tabular}{|c|c|c|}
\hline Objective local food environment measures & OR $[95 \% \mathrm{Cl}]$ & $p$ \\
\hline \multicolumn{3}{|l|}{ Fruit/vegetable markets in $400 \mathrm{~m}$} \\
\hline None & 1.00 & \\
\hline I store & $\mathrm{I} .18[0.96,1.46]$ & .117 \\
\hline$>$ I stores & $1.51[1.14,1.99]$ & .004 \\
\hline \multicolumn{3}{|l|}{ Meat markets in $400 \mathrm{~m}$} \\
\hline No & 1.00 & \\
\hline Yes & $0.74[0.62,0.90]$ & .002 \\
\hline $\begin{array}{l}\text { Supermarkets/groceries (medium/large size) } \\
\text { in } 400 \mathrm{~m}\end{array}$ & $1.05[1.01,1.10]$ & .013 \\
\hline \multicolumn{3}{|l|}{ Fruit/vegetable markets in $800 \mathrm{~m}$} \\
\hline None & 1.00 & \\
\hline I store & $1.91[1.05,3.46]$ & .035 \\
\hline$>$ I stores & $2.93[1.69,5.07]$ & .000 \\
\hline \multicolumn{3}{|l|}{ Meat markets in $800 \mathrm{~m}$} \\
\hline No & 1.00 & \\
\hline Yes & $0.74[0.60,0.91]$ & .004 \\
\hline
\end{tabular}

Note. $\mathrm{OR}=$ odds ratio; $\mathrm{Cl}=$ confidence interval. Boldfaced $p$ values indicate statistical significance $(p<.05)$.

stores echoed similar findings from national studies of predominantly African American and low-income Hispanic neighborhoods in the United States (Lucan et al., 2014; Powell et al., 2007).

In predicting how the objective measures of local food environment align with the participant's perception of healthy food access in their neighborhood, we found that the presence of medium-/large-size supermarkets/groceries within 400-m radius buffer significantly increased participants' odds of perceiving that the fresh fruits and vegetables in the neighborhood are of high quality. Similarly, the presence of medium-/largesize supermarkets/groceries in both the 400-m and $800-\mathrm{m}$ residential radii significantly increased participants' odds of perceiving that a large selection of low-fat products is available
Table 5. Multivariate Binary Logistic Regressions for Predicting Perceived Availability and Selection of Low-Fat Products in the Neighborhood.

\begin{tabular}{|c|c|c|}
\hline Objective local food environment measures & OR $[95 \% \mathrm{Cl}]$ & $p$ \\
\hline \multicolumn{3}{|l|}{ Fruit/vegetable markets in $400 \mathrm{~m}$} \\
\hline None & 1.00 & \\
\hline I store & $1.23[1.00,1.5 \mathrm{I}]$ & .051 \\
\hline$>1$ stores & $1.38[1.05,1.81]$ & .020 \\
\hline \multicolumn{3}{|l|}{ Meat markets in $400 \mathrm{~m}$} \\
\hline No & 1.00 & \\
\hline Yes & $0.83[0.69,0.99]$ & .042 \\
\hline $\begin{array}{l}\text { Supermarkets/groceries (medium/large size) } \\
\text { in } 400 \mathrm{~m}\end{array}$ & $1.05[1.01,1.10]$ & .015 \\
\hline \multicolumn{3}{|l|}{ Fruit/vegetable markets in $800 \mathrm{~m}$} \\
\hline None & 1.00 & \\
\hline I store & $\mathrm{I} .30[0.7 \mathrm{I}, 2.40]$ & .395 \\
\hline$>1$ stores & $1.98[1.13,3.48]$ & .018 \\
\hline \multicolumn{3}{|l|}{ Meat markets in $800 \mathrm{~m}$} \\
\hline No & 1.00 & \\
\hline Yes & $0.82[0.67,1.00]$ & .051 \\
\hline $\begin{array}{l}\text { Supermarkets/groceries (medium/large size) } \\
\text { in } 800 \mathrm{~m}\end{array}$ & $1.13[1.08,1.19]$ & .000 \\
\hline Supermarkets/groceries (small size) in $800 \mathrm{~m}$ & $0.97[0.95,0.98]$ & .000 \\
\hline
\end{tabular}

Note. $\mathrm{OR}=$ odds ratio; $\mathrm{Cl}=$ confidence interval. Boldfaced $p$ values indicate statistical significance $(p<.05)$.

in the neighborhood. However, the presence of small-size supermarkets/groceries, which accounted for $71 \%$ of the food environment landscape assessed in our study, did not have much influence on the participants' perception of the availability and selection of fresh fruits and vegetables or low-fat products in the neighborhood. A possible explanation for this finding is that the medium-/large-size supermarkets/groceries, which accounted for $21 \%$ of the food environment landscape assessed in this study, may offer higher quality and greater variety of healthier food products at more affordable prices than those offered in small-size supermarkets/groceries (Chung \& Myers, 1999; Glanz, Sallis, Saelens, \& Frank, 2007). A similar observation has been reported in a mixed methods study of urban adults in Philadelphia who chose to shop at large chain supermarkets because of the greater variety of healthful foods and sometimes lower prices, including opting for more distant stores from home given the variety of healthful foods offered (Cannuscio et al., 2013).

Although meat markets assessed in our study carry healthier food items, our study participants were consistently less likely to associate fresh fruits and vegetables or low-fat products with meat markets. It is possible that our participants' perception of their local food environment may have more to do with their preference on where they shop in the neighborhood. Fruit/vegetable markets accounted for only $7 \%$ of the food neighborhood landscape assessed in our study. However, their presence in both the $400-\mathrm{m}$ and $800-\mathrm{m}$ radii significantly increased participants' odds of perceiving the availability, selection, and quality of fresh fruits and vegetables as well as the availability and selection of low-fat products in the neighborhood. 
Our finding that Hispanic participants did not consume the federal minimum daily recommendation of two servings of fruits and three servings of vegetables was consistent with findings from a national study that Americans do not eat enough fruits and vegetables (Moore \& Thompson, 2015). It is possible that other factors such as cultural background, socioeconomic status, personal preference, daily activity space, frequently visited destinations, and travel routines can influence their food shopping and food purchasing decisions. The nutritional analyses of food receipts conducted by the Robert Wood Johnson Foundationfunded Salud America! research network reported that lowincome Spanish-speaking Latino families spend a third of their income on food, with many of the food being higher in calorie, lower in fiber, and higher in fat, sodium, and carbohydrates (Cortés, Millán-Ferro, Schneider, Vega, \& Caballero, 2013).

This study had several strengths, which included the use of both objective and perceived measures of healthy food access. The objective measures of the local food environment involved the identification of relevant food retailers that carry healthier food items such as fresh fruits and vegetables or low-fat products, and included the use of applicable NAICS codes and descriptions to distinguish supermarkets/groceries from convenience stores to provide a greater level of specificity. Ground truth field validation confirmed the stores' food outlet classification and location address as well as the availability of healthy food items in the store.

The use of Euclidean-based distance enabled the identification of food source exposures within a participant's 400-m and 800-m residential radii buffers. This supported the spatial modeling of person-level local food environments where study participants could conveniently buy healthy foods within a 5 -minute or 10-minute walk from their home. In addition, the participants' perceptions of healthy food access were assessed using previously validated self-reported measures (Ma et al., 2013).

There were several limitations. The cross-sectional data and observational study design limited our ability to demonstrate causality. In addition, the study definition of food environment was based on food retailers with physical address, thus excluding sidewalk produce vendors, Green Cart mobile vendors, and farmers' markets given their mobile locations and/or seasonal hours, and resulting in the potential to underestimate healthy food access. Furthermore, the use of Euclidean-based distance to calculate proximity between the participants' home and healthier food outlets does not factor in the influence of cliffs in some areas, which may result in an overestimation of healthy food access. This analysis also did not examine the relationship between local food environment and fruit and vegetable consumption. Although the survey data were collected several years ago, the descriptive and methodological nature of this study does not influence the significance or relevance of the findings.

\section{Conclusion}

Given that little is known about the relationship between local food environment and perceived healthy food access among
Hispanics, the study findings contribute to understanding this relationship. In particular, findings that living within walking distance to medium-/large-size supermarkets/groceries and fruit/vegetable markets increased the odds of perceiving healthy food access have important policy implications since perceived access is fundamental to healthy eating and consequently on obesity and diet-related health conditions. More research is needed to gain a more in-depth understanding of the local food environment for Hispanics and to examine the relationships between local food environment and fruit and vegetable consumptions as well as obesity and diet-related chronic diseases.

\section{Acknowledgments}

We gratefully acknowledge the support and contribution of Dr. Arlene Smaldone, Dr. Andrew Rundle, Dr. Sunmoo Yoon, and Niurka SueroTejeda to the work presented here.

\section{Declaration of Conflicting Interests}

The author(s) declared no potential conflicts of interest with respect to the research, authorship, and/or publication of this article.

\section{Funding}

The author(s) disclosed receipt of the following financial support for research, authorship, and/or publication of this article: This study was supported by the Washington Heights/Inwood Informatics Infrastructure for Comparative Effectiveness Research (WICER; R01HS019853), WICER 4 U (R01HS022961), and the Reducing Health Disparities Through Informatics training grant (T32NR007969).

\section{ORCID iD}

Manuel C. Co Jr., PhD, MS, RN, CPHIMS (D) http://orcid.org/00000002-0005-2586

\section{References}

Auchincloss, A. H., Roux, A. V. D., Mujahid, M. S., Shen, M., Bertoni, A. G., \& Carnethon, M. R. (2009). Neighborhood resources for physical activity and healthy foods and incidence of type 2 diabetes mellitus: The multi-ethnic study of atherosclerosis. Archives of Internal Medicine, 169, 1698-1704.

Ball, K., Timperio, A., \& Crawford, D. (2009). Neighbourhood socioeconomic inequalities in food access and affordability. Health \& Place, 15, 578-585. Retrieved from http://www.sciencedirect. com/science/article/pii/S1353829208001160

Barnes, T. L., Bell, B. A., Freedman, D. A., Colabianchi, N., \& Liese, A. D. (2015). Do people really know what food retailers exist in their neighborhood? Examining GIS-based and perceived presence of retail food outlets in an eight-county region of South Carolina. Spatial and Spatio-Temporal Epidemiology, 13(13), 31-40. doi:10.1016/j.sste.2015.04.004

Bauer, K. W., Larson, N. I., Nelson, M. C., Story, M., \& NeumarkSztainer, D. (2009). Fast food intake among adolescents: Secular and longitudinal trends from 1999 to 2004. Preventive Medicine, 48, 284-287. Retrieved from http://www.sciencedirect.com/sci ence/article/pii/S0091743508006762

Black, J. L., Macinko, J., Dixon, L. B., \& Fryer, J. G. E. (2010). Neighborhoods and obesity in New York City. Health \& Place, 
16, 489-499. Retrieved from http://www.sciencedirect.com/sci ence/article/pii/S1353829209001518

Bodor, J. N., Rice, J. C., Farley, T. A., Swalm, C. M., \& Rose, D. (2010a). Disparities in food access: Does aggregate availability of key foods from other stores offset the relative lack of supermarkets in African-American neighborhoods? Preventive Medicine, 51, 63-67. Retrieved from http://www.sciencedirect.com/science/arti cle/pii/S009174351000160X

Bodor, J. N., Rice, J. C., Farley, T. A., Swalm, C., \& Rose, D. (2010b). The association between obesity and urban food environments. Journal of Urban Health, 87, 771-781. doi:10.1007/s11524-0109460-6

Bodor, J. N., Rose, D., Farley, T. A., Swalm, C. M., \& Scott, S. K. (2007). Neighbourhood fruit and vegetable availability and consumption: The role of small food stores in an urban environment. Public Health Nutrition, 11, 413-420.

Cannuscio, C. C., Tappe, K., Hillier, A., Buttenheim, A., Karpyn, A., \& Glanz, K. (2013). Urban food environments and residents' shopping behaviors. American Journal of Preventive Medicine, 45, 606-614. doi:10.1016/j.amepre.2013.06.021

Casey, R., Oppert, J. M., Weber, C., Charreire, H., Salze, P., Badariotti, D., . . . Simon, C. (2014). Determinants of childhood obesity: What can we learn from built environment studies? Food Quality and Preference, 31, 164-172. doi:10.1016/j.foodqual.2011.06.003

Caspi, C. E., Kawachi, I., Subramanian, S. V., Adamkiewicz, G., \& Sorensen, G. (2012). The relationship between diet and perceived and objective access to supermarkets among low-income housing residents. Social Science \& Medicine, 75, 1254-1262.

Centers for Disease Control and Prevention. (2005). 5 a Day works. Atlanta, GA: U.S. Department of Health and Human Services. Retrieved from https://www.cdc.gov/nccdphp/dnpa/nutrition/ health_professionals/programs/5aday_works.pdf

Chung, C., \& Myers, S. L. (1999). Do the poor pay more for food? An analysis of grocery store availability and food price disparities. Journal of Consumer Affairs, 33, 276-296.

Cortés, D. E., Millán-Ferro, A., Schneider, K., Vega, R. R., \& Caballero, A. E. (2013). Food purchasing selection among low-income, Spanish-speaking Latinos. American Journal of Preventive Medicine, 44(Suppl. 3), S267-S273. doi:10.1016/j.amepre.2012.11.012

Dubowitz, T., Ghosh-Dastidar, M., Eibner, C., Slaughter, M. E., Fernandes, M., Whitsel, E. A., ... Escarce, J. J. (2012). The Women's Health Initiative: The food environment, neighborhood socioeconomic status, BMI, and blood pressure. Obesity, 20, 862-871. doi: 10.1038/oby.201

Dubowitz, T., Zenk, S. N., Ghosh-Dashtidar, B., Cohen, D. A., Beckman, R., Hunter, G., .. Collins, R. L. (2015). Healthy food access for urban food desert residents: Examination of the food environment, food purchasing practices, diet, and body mass index. Public Health Nutrition, 18, 2220-2230. doi:10.1017/S1368980014002742

Fox, M. K., Dodd, A. H., Wilson, A., \& Gleason, P. M. (2009). Association between school food environment and practices and body mass index of U.S. public school children. Journal of the American Dietetic Association, 109(2 Suppl.), S108-S117. doi: 10.1016/j.jada.2008.10.065

Glanz, K., Sallis, J. F., Saelens, B. E., \& Frank, L. D. (2007). Nutrition Environment Measures Survey in Stores (NEMS-S): Development and evaluation. American Journal of Preventive Medicine, 32, 282-289. doi:10.1016/j.amepre.2006.12.019

Gustafson, A. A., Sharkey, J., Samuel-Hodge, C. D., Jones-Smith, J., Folds, M. C., Cai, J., \& Ammerman, A. S. (2011). Perceived and objective measures of the food store environment and the association with weight and diet among low-income women in North Carolina. Public Health Nutrition, 14, 1032-1038.

Guthrie, J. (2004, October). Understanding fruit and vegetable choices: Economic and behavioral influences (Agriculture Information Bulletin No. 792-1). Washington, DC: U.S. Department of Agriculture, Economic Research Service. Retrieved from https:// www.ers.usda.gov/webdocs/publications/42564/19255_aib792-1. pdf? $\mathrm{v}=41428$

Harris, P. A., Taylor, R., Thielke, R., Payne, J., Gonzalez, N., \& Conde, J. G. (2009). Research Electronic Data Capture (REDCap): A metadata-driven methodology and workflow process for providing translational research informatics support. Journal of Biomedical Informatics, 42, 377-381. doi:10.1016/j.jbi.2008.08.010

Horowitz, C. R., Colson, K. A., Hebert, P. L., \& Lancaster, K. (2004). Barriers to buying healthy foods for people with diabetes: Evidence of environmental disparities. American Journal of Public Health, 94, 1549-1554. doi:10.2105/AJPH.94.9.1549

Hosmer, D. W., \& Lemeshow, S. (2000). Assessing the fit of the model. In Applied logistic regression (pp. 143-202). Hoboken, NJ: John Wiley. doi:10.1002/0471722146.ch5

Jack, D., Neckerman, K. M., Schwartz-Soicher, O., Lovasi, G. S., Quinn, J., Richards, C., . . Rundle, A. (2013). Socio-economic status, neighbourhood food environments and consumption of fruits and vegetables in New York City. Public Health Nutrition, 16, 1197-1205. doi:10.1017/S1368980012005642

King, L., Hinterland, K., Dragan, K., Driver, C., Harris, T., Gwynn, R.,... Bassett, M. (2015). Community Health Profiles 2015, Manhattan Community District 12: Washington Heights and Inwood. New York, NY: Department of Health and Mental Hygiene. Retrieved from https://www1.nyc.gov/assets/doh/down loads/pdf/data/2015chp-mn12.pdf

Laraia, B. A., Hendrickson, B., \& Zhang, Y. T. (2015). Local food environments and dietary intake. In K. B. Morland (Ed.), Local food environments: Food access in America (pp. 121-166). Boca Raton, FL: CRC Press.

Larson, N. I., Story, M. T., \& Nelson, M. C. (2009). Neighborhood environments: Disparities in access to healthy foods in the U.S. American Journal of Preventive Medicine, 36, 74-81.e10. Retrieved from http://www.sciencedirect.com/science/article/pii/ S0749379708008386

Liese, A. D., Weis, K. E., Pluto, D., Smith, E., \& Lawson, A. (2007). Food store types, availability, and cost of foods in a rural environment. Journal of American Dietetic Association, 107, 1916-1923. doi:10.1016/j.jada.2007.08.012

Lucan, S. C., Hillier, A., Schechter, C. B., \& Glanz, K. (2014). Objective and self-reported factors associated with food-environment perceptions and fruit-and-vegetable consumption: A multilevel analysis. Preventive Chronic Disease, 11(1), E47. doi:10.5888/ pcd11.130324

Ma, X., Barnes, T. L., Freedman, D. A., Bell, B. A., Colabianchi, N., \& Liese, A. D. (2013). Test-retest reliability of a questionnaire 
measuring perceptions of neighborhood food environment. Health \& Place, 21, 65-69. doi:10.1016/j.healthplace.2013.01.008

Mickey, R. M., \& Greenland, S. (1989). The impact of confounder selection criteria on effect estimation. American Journal of Epidemiology, 129, 125-137. Retrieved from http://aje.oxfordjournals. org/content/129/1/125.abstract

Moore, L. V., Diez Roux, A. V., \& Brines, S. (2008). Comparing perception-based and geographic information system (GIS)-based characterizations of the local food environment. Journal of Urban Health, 85, 206-216. doi:10.1007/s11524-008-9259-x

Moore, L. V., \& Thompson, F. E. (2015). Adults meeting fruit and vegetable intake recommendations: United States, 2013. Morbidity and Mortality Weekly Report, 64(26), 709-713.

Morland, K. B., Diez Roux, A. V., \& Wing, S. (2006). Supermarkets, other food stores, and obesity: The atherosclerosis risk in communities study. American Journal of Preventive Medicine, 30, 333-339. doi:10.1016/j.amepre.2005.11.003

Morland, K. B., \& Evenson, K. R. (2009). Obesity prevalence and the local food environment. Health \& Place, 15, 491-495.

Morland, K. B., \& Filomena, S. (2007). Disparities in the availability of fruits and vegetables between racially segregated urban neighbourhoods. Public Health Nutrition, 10, 1481-1489.

Morland, K. B., Wing, S., \& Diez Roux, A. V. (2002). The contextual effect of the local food environment on residents' diets: The atherosclerosis risk in communities study. American Journal of Public Health, 92, 1761-1767.

Mujahid, M. S., Roux, A. V. D., Morenoff, J. D., Raghunathan, T. E., Cooper, R. S., Ni, H., \& Shea, S. (2008). Neighborhood characteristics and hypertension. Epidemiology, 19, 590-598.

Neckerman, K. M., Bader, M. D. M., Richards, C. A., Purciel, M., Quinn, J. W., Thomas, J. S., ... Rundle, A. (2010). Disparities in the food environments of New York City public schools. American Journal of Preventive Medicine, 39, 195-202. doi:10.1016/j. amepre.2010.05.004

Odoms-Young, A. M., Zenk, S. N., \& Mason, M. M. (2009). Measuring food availability and access in African-American communities: Implications for intervention and policy. American Journal of Preventive Medicine, 36, S145-S150. doi:10.1016/ j.amepre.2009.01.001

Passel, J. S., Cohn, D., \& Lopez, M. H. (2011, March 24). Hispanics account for more than half of nation's growth in past decade. Washington, DC: Pew Hispanic Center. Retrieved from http:// www.pewhispanic.org/files/reports/140.pdf

Powell, L. M., Slater, S., Mirtcheva, D., Bao, Y., \& Chaloupka, F. J. (2007). Food store availability and neighborhood characteristics in the United States. Preventive Medicine, 44, 189-195. doi:10.1016/ j.ypmed.2006.08.008
Rundle, A., Neckerman, K. M., Freeman, L., Lovasi, G. S., Purciel, M., Quinn, J., ... Weiss, C. (2009). Neighborhood food environment and walkability predict obesity in New York City. Environmental Health Perspectives, 117, 442-447.

Schulz, A., Mentz, G., Johnson-Lawrence, V., Israel, B. A., Max, P., Zenk, S. N., . . Marans, R. W. (2013). Independent and joint associations between multiple measures of the built and social environment and physical activity in a multi-ethnic urban community. Journal of Urban Health, 90, 872-887.

Smoyer-Tomic, K. E., Spence, J. C., Raine, K. D., Amrhein, C., Cameron, N., \& Yasenovskiy, V., ... Healy, J. (2008). The association between neighborhood socioeconomic status and exposure to supermarkets and fast food outlets. Health \& Place, 14, 740-754. doi:10.1016/j.healthplace.2007.12.001

Stark, J. H., Neckerman, K. M., Lovasi, G. S., Konty, K., Quinn, J., Arno, P., . . Rundle, A. (2013). Neighbourhood food environments and body mass index among New York City adults. Journal of Epidemiology \& Community Health, 67, 736-742. doi:10.1136/ jech-2013-202354

Thornton, R. L. J., Glover, C. M., Cené, C. W., Glik, D. C., Henderson, J. A., \& Williams, D. R. (2016). Evaluating strategies for reducing health disparities by addressing the social determinants of health. Health Affairs, 35, 1416-1423. doi:10.1377/hlthaff. 2015.1357

U.S. Census Bureau. (2013). North American Industry Classification System. Washington, DC: Author. Retrieved from https://www. census.gov/eos/www/naics/2017NAICS/2017_NAICS_Manual.pdf

U.S. Census Bureau. (2015). Quick facts: New York. Retrieved from https://www.census.gov/quickfacts/table/RHI725215/36

Walker, R. E., Keane, C. R., \& Burke, J. G. (2010). Disparities and access to healthy food in the United States: A review of food deserts literature. Health \& Place, 16, 876-884.

Zenk, S. N., Schulz, A. J., Israel, B. A., James, S. A., Bao, S., \& Wilson, M. L. (2005). Neighborhood racial composition, neighborhood poverty, and the spatial accessibility of supermarkets in metropolitan Detroit. American Journal of Public Health, 95, 660-667.

Zenk, S. N., Lachance, L. L., Schulz, A. J., Mentz, G., Kannan, S., \& Ridella, W. (2009). Neighborhood retail food environment and fruit and vegetable intake in a multiethnic urban population. American Journal of Health Promotion, 23, 255-264. doi:10.4278/ajhp. 071204127

Zenk, S. N., Thatcher, E., Reina, M., \& Odoms-Young, A. (2015). Local food environments and diet-related health outcomes: A systematic review of local food environments, body weight, and other diet-related health outcomes. In K. B. Morland (Ed.), Local food environments: Food access in America (pp. 167-204). Boca Raton, FL: CRC Press. 